\title{
Jim completes Channel swim
}

advances in concepts, technology, materials, and equipment « have changed the way endodontics is being practised today. These advances have made it possible to efficiently perform successful endodontic treatment with improved precision and predictability and with greater acceptance and comfort.'

This 50th anniversary edition of the textbook originally edited by John Ingle was a little late being released but is nonetheless a welcome update. Its vivid yellow colour harks back to the yellow cover of the very first edition, a colour originally suggested by Ingle's wife, Joyce. Even larger than its predecessor with 1,326 pages and 1,729 colour illustrations the $5 \mathrm{~kg}$ hard copy version this time has at least been split into two volumes. Contributors from all parts of the world have collaborated on 40 chapters split into just three sections: the Science of Endodontics; the Practice of Endodontics; Interdisciplinary Endodontics. As well as updates to the previous text this edition includes 12 completely new chapters on periradicular disease, dental innervations and pain of pulpal origin, CBCT, MRI, preparation for endodontic treatment, endodontics in teeth with anatomical variations, long-term success, teeth with immature apices, regenerative endodontics, intentional replantation of endodontically-treated teeth, endodontics in the elderly patient and finally, endodontics in the paediatric patient. https://tinyurl.com/ebooks-endo
In the 25 September issue of the $B D J$ we reported that dentist Jim Lafferty was preparing to swim the English Channel to raise funds for Dentaid (Volume 229, issue 6).

Despite crashing waves, exhaustion, hidden rocks and a jellyfish sting on the face, Jim completed the swim on 14 September and at the time of writing had raised $£ 6,904$ for the charity.

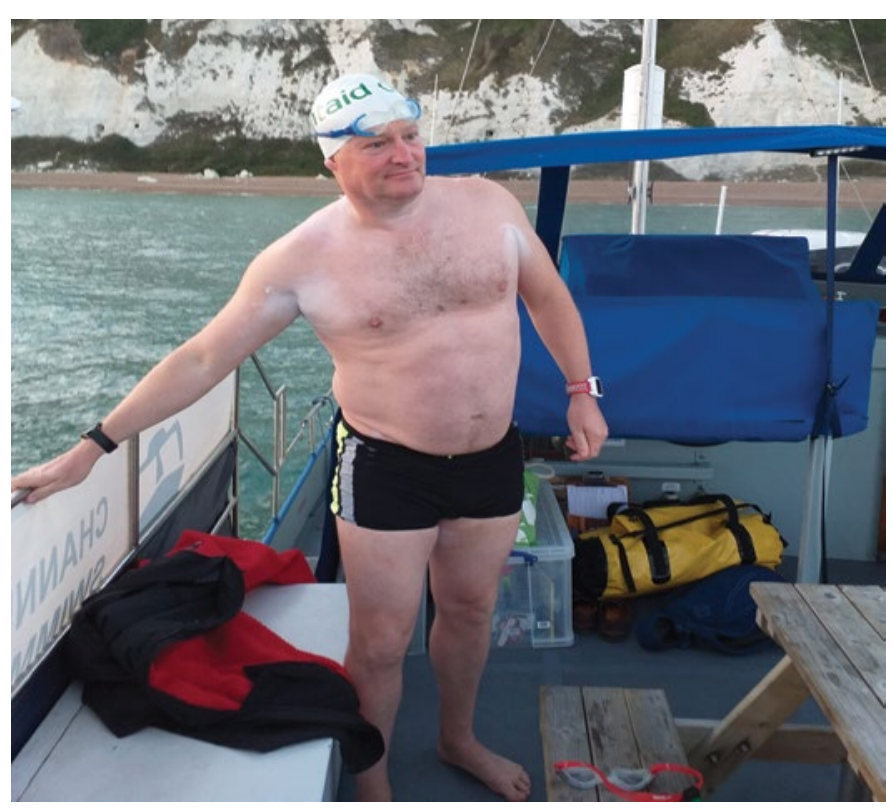

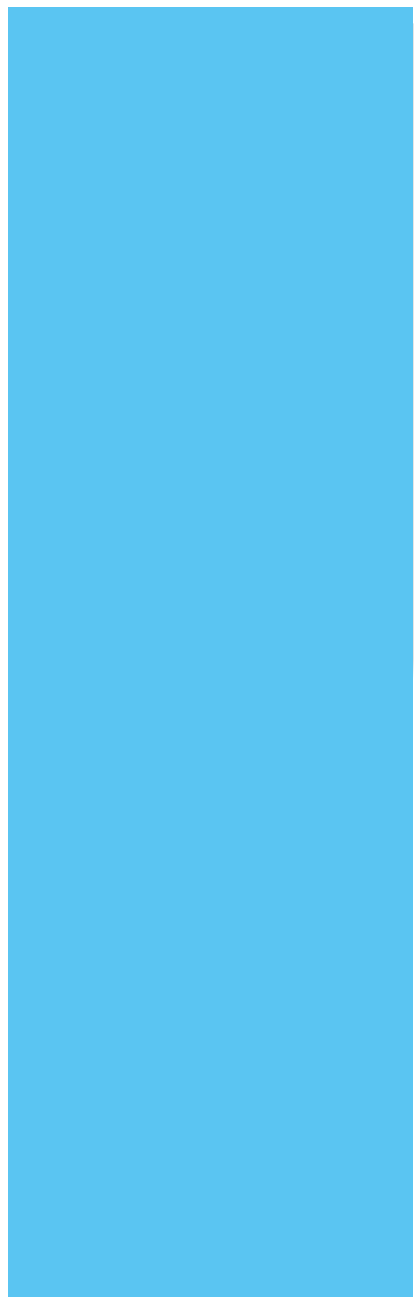

